\title{
Significance of minor ST segment and T wave changes in the resting electrocardiogram of asymptomatic subjects
}

\author{
M JOY, D W TRUMP \\ From UK Civil Aviation Authority, CAA House, London
}

SUMMARY Sixteen thousand resting electrocardiograms were performed on 14000 United Kingdom professional aircrew and air traffic control officers over a two-year period; 103 asymptomatic men with minor ST segment and $\mathrm{T}$ wave changes at rest were assessed by exercise electrocardiography and 19 responded abnormally. Five subjects had proven coronary artery disease, one hypertrophic obstructive cardiomyopathy, and one left ventricular dilatation on echocardiography. Eleven subjects were not investigated, of whom three had strongly positive exercise responses. One subject had a false positive response and assuming a false negative response of less than 2 per cent, then a sensitivity of 80.0 per cent, a specificity of 89.1 per cent, a predictive value for the exercise electrocardiogram of 44.46 per cent and for the resting electrocardiogram of 7.8 per cent is obtained.

$\mathrm{T}$ wave changes induced by hyperventilation were common $(53.4 \%$ of all). Ten $(18.2 \%)$ subjects with hyperventilation-induced $T$ wave changes responded abnormally to exercise, three having angiographically proven coronary artery disease lending little support to the contention that the two entities rarely coexist.

In spite of the low return from routine electrocardiograms in a population with a low prevalence of coronary artery disease, three-eighths of those with significant coronary artery disease presented with minor ST segment and $\mathrm{T}$ wave changes on their resting electrocardiograms.

The resting electrocardiogram has become an accepted part of routine clinical examination of asymptomatic subjects. Certain occupational groups, however, are subjected to regular electrocardiographic screening in an attempt to detect cardiovascular problems which might predispose to sudden incapacitation while on duty. Unfortunately, the resting electrocardiogram is neither sensitive nor reliable for the detection of the prevailing problem of occult coronary artery disease, and minor electrocardiographic changes of doubtful significance are quite common. Anomalies of the ST segment and T waves (ST-T) have recently been reported in 3.1 per cent of Royal Air Force, ${ }^{1}$ and 2.9 per cent of civilian aircrew electrocardiograms, ${ }^{23}$ prompting us to review their diagnostic value.

Changes on exercise in the configuration of the ST segment are generally regarded as being the most consistently reliable indicator of exerciseinduced myocardial ischaemia, ${ }^{45}$ and may be of both diagnostic and prognostic significance. ${ }^{6}$ ? Exercise-induced $T$ wave changes on the other hand are of much less certain significance and are not associated with significantly higher mortality. ${ }^{6}$ Minor ST-T changes in the resting electrocardiogram have been variously reported as being of important, ${ }^{8}$ some, ${ }^{9}$ and no prognostic significance. ${ }^{10}$ They have also been described in a number of conditions including hyperventilation, ${ }^{11}{ }^{12}$ the hyperkinetic heart syndrome, ${ }^{13}$ changes in posture, ${ }^{11}$ lesions of the central nervous system, ${ }^{14}$ cardiac sympathetic nerve stimulation ${ }^{15}$ or ablation, ${ }^{16}$ abnormalities of left ventricular wall motion in the absence of coronary artery disease, ${ }^{17}$ and in athletes. ${ }^{18}$ Somerville and his group at the Middlesex Hospital have extensively investigated the effects of emotion, ${ }^{1} 19$ on the resting electrocardiogram and have suggested myocardial sensitivity to circulating catecholamines as a possible mechanism. It is not difficult to understand a pilot's apprehension in presenting himself for routine electrocardiography 
and it was in this perspective that we also evaluated the significance of the $T$ wave changes seen not infrequently on their recordings.

\section{Subjects and methods}

Some 34000 routine medical examinations were carried out on behalf of the United Kingdom Civil Aviation Authority during the two years ending June 1979 by 103 authorised medical examiners on 14000 professional aircrew and air traffic control officers. These subjects were examined six-monthly or annually (depending on licence) and underwent resting electrocardiography at six-, 12-, 24-, or 60monthly intervals (depending on age). During this period nearly 16000 electrocardiograms were recorded by the authorised medical examiners on 20 different models of recording apparatus, the majority of recordings being made on machines capable of reaching the American Heart Association standard. The recordings were interpreted by three physicians, three-fifths of them being interpreted by the first author. During this period approximately 1200 aircrew and air traffic control officers underwent specialist scrutiny at CAA House, two-thirds on account of possible cardiovascular disease, and two-thirds of these were reviewed by the first author. Two hundred and forty underwent treadmill electrocardiography, 192 being professional aircrew and air traffic control officers; $103(53.6 \%)$ of these had presented with minor ST-T changes in the routine resting electrocardiogram and are the subject of this report. All subjects were asymptomatic men on no treatment apart from four who were on thiazide diuretics for mild hypertension, and one each on allopurinol and thyroxine.

\section{RESTING ELECTROCARDIOGRAPHY}

A 12 lead electrocardiogram was recorded in the recumbent position in all cases on a Marquette 3100 three-channel system at $25 \mathrm{~mm}$ per second. Highspeed recordings in different postures and after hyperventilation or beta blockade were also made, but not routinely. The subjects were classified into five groups according to the leads in which abnormalities were seen on the referral electrocardiogram.

\section{EXERCISE ELECTROCARDIOGRAPHY}

Maximal treadmill electrocardiograms were performed according to the Bruce procedure, ${ }^{20}{ }^{21}$ the end point being exhaustion. Chest pain or significant rhythm disturbance were not observed, and informed signed consent was obtained from all subjects. An Avionics E15 treadmill was used in conjunction with an Avionics 3000 three-channel
Table Classification of electrocardiographic response to exercise (sigma) (after Goldschlager et al. ${ }^{4}$ )

\begin{tabular}{lr} 
Normal & $\sigma 0$ \\
$\begin{array}{l}\text { Non-specific (J point depression) } \\
\text { ST segment depression } \geqslant 1.5 \mathrm{~mm} 80 \mathrm{~ms} \text { after the }\end{array}$ & $\sigma 1$ \\
$\begin{array}{l}\text { J point } / \mathrm{ST} \text { depression } \geqslant 1.0 \mathrm{~mm} \text { with ST slope }<1 \mathrm{mV} / \mathrm{s} \\
\text { or both }\end{array}$ & $\sigma 2$ \\
$\begin{array}{l}\text { J point depression } \geqslant 1.0 \mathrm{~mm} \text { with ST downslope } / J \text { point } \\
\text { depression } \geqslant 1.0 \mathrm{~mm} \text { with flat ST segments }\end{array}$ & $\sigma 3$ \\
\hline
\end{tabular}

oscillographic monitor. Three leads, CM4, 5, and 6, were used with Cardiogard 1250 non-disposable electrodes after suitable skin preparation; 5 to 10 second electrocardiograph samples were taken in the recumbent position at rest, after forced hyperventilation for 15 to 20 seconds in the sitting position, and after each minute of exercise. Recordings were made at the end of the test and during each of 10 minutes of recovery. The recordings were interpreted twice and consensus obtained.

The ST-T changes were categorised according to the responses to exercise (Table) and to hyperventilation (Fig. 1). Classification of the changes on hyperventilation designated tau ( $\tau$ ), was based on the loss $\geqslant 50$ per cent ( $\tau 1)$, reversal ( $\tau 2)$, or enhancement ( $\tau 3)$ of the notional epicardial/ endocardial $\mathrm{T}$ wave gradient. Classification of the exercise responses, designated sigma $(\sigma)$, was based
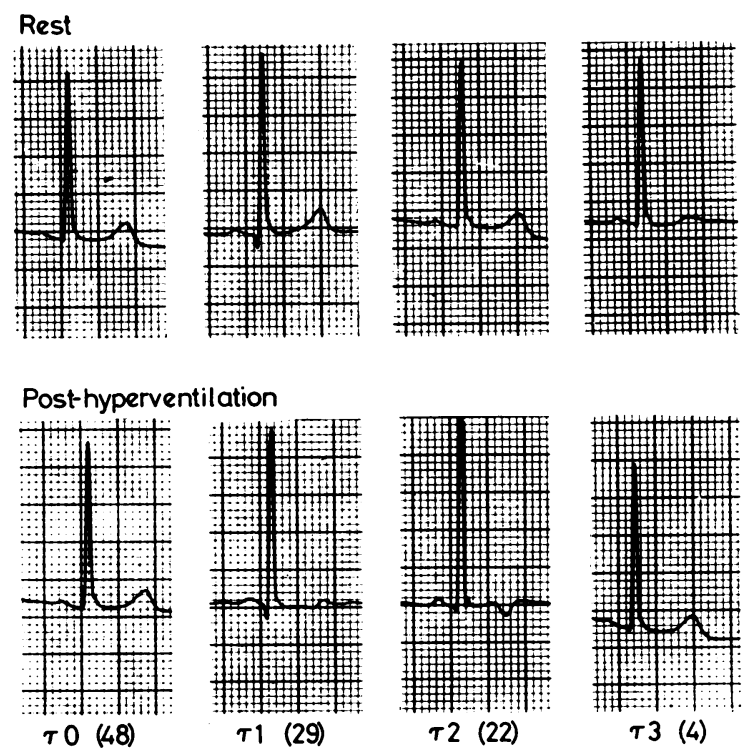

Fig. 1 Responses to hyperventilation were classified as nil $(\tau 0)$; loss of $T$ wave voltage $\geqslant 50$ per cent $(\tau 1)$; $S T$ segment downslope $/ T$ wave inversion ( $\tau 2)$; and $T$ wave enhancement ( $\tau 3)$. Numbers in each group are given in parentheses. 
on the observations of Goldschlager et al. ${ }^{4}$ Their responses type $1 \mathrm{~A}$ and $1 \mathrm{~B}$, bracketed together as $\sigma 3$, were associated with a 93 per cent specificity for coronary artery disease, albeit in symptomatic subjects. Inclusion of their type II response $(\sigma 2)$ reduced this specificity to 82 per cent. $J$ point depression during exercise is generally considered to be a normal variant ${ }^{22}$ but was separately categorised $(\sigma 1)$ to examine any possible relation with hyperventilatory phenomena. The heart rate responses were measured from the recordings, the chart speed being regularly checked and the recording system optimally damped.

\section{FURTHER INVESTIGATION}

Further investigation could not be insisted upon for licensing purposes though refusal carried potential licensing implications. Ten $\mathrm{M}$-mode echocardiograms, four thallium-201 scans, and 11 coronary angiograms were performed using standard techniques by the cardiologists listed among the acknowledgements. Three subjects refused coronary angiography and eight further investigations were not performed because of impending retirement or for operational reasons.

\section{OTHER DOCUMENTED CARDIOVASCULAR INCIDENTS}

The documents of all aircrew and air traffic control officers who had been made unfit for cardiovascular reasons during the period under review were scrutinised.

\section{Results}

One hundred and three asymptomatic men with a mean age of 45.66 years \pm 1.2 SEM (range 18 to 68) were assessed for minor ST-T changes in their routine resting electrocardiograms. In none did the blood pressure exceed $180 / 100 \mathrm{mmHg}$; none was on treatment apart from those recorded above. Three were noted to have mid-systolic clicks and one of these was subsequently confirmed to have mitral valve prolapse as well as coronary artery disease on angiography. In 93 subjects $(90.3 \%)$ the anomaly on the referral electrocardiogram was confirmed on a further recording; in the remaining $10(9.7 \%)$ the recording was normal. In certain instances there was reasonable evidence of technical artefact such as overdamping but this did not deter exercise evaluation in view of licensing implications. Since the emphasis on routine screening lay towards the detection of possible causes of sudden incapacitation, the threshold for the assessment of electrocardiographic anomalies tended to fall with age. This tendency together with the increased electro- cardiographic scrutiny with age will have skewed the age distribution in this study to the right.

\section{RESTING ELECTROCARDIOGRAM AND}

EXERCISE FINDINGS

Fig. 2 illustrates the relation between anomalies on presentation and subsequent exercise findings. If isolated $\mathrm{J}$ point depression is regarded as normal, then $84(81.6 \%)$ of the subjects responded normally to exercise and $19(18.4 \%)$ responded abnormally. Isolated septal lead changes are generally regarded as benign and only three instances were seen, all with normal exercise responses. Fourteen subjects presented with anterolateral lead changes at rest and all but one responded normally to exercise. Subjects with isolated left chest lead changes produced four positive responses out of $19(21 \cdot 1 \%)$ while subjects with inferolateral lead changes produced five positive responses out of $28(17 \cdot 8 \%)$. Finally, in those subjects with minor ST-T changes in multiple leads, nine out of $39(23.1 \%)$ had a positive response to exercise.

EVALUATION OF SUBJECTS WITH A POSITIVE EXERCISE RESPONSE

Nineteen subjects were considered to have a positive response ( $\sigma 2$ or $\sigma 3$ ) to exercise. One of two subjects with a $\sigma 2$ response and four out of five with a $\sigma 3$ response had significant coronary artery disease as judged by angiography or thallium-201 scanning.

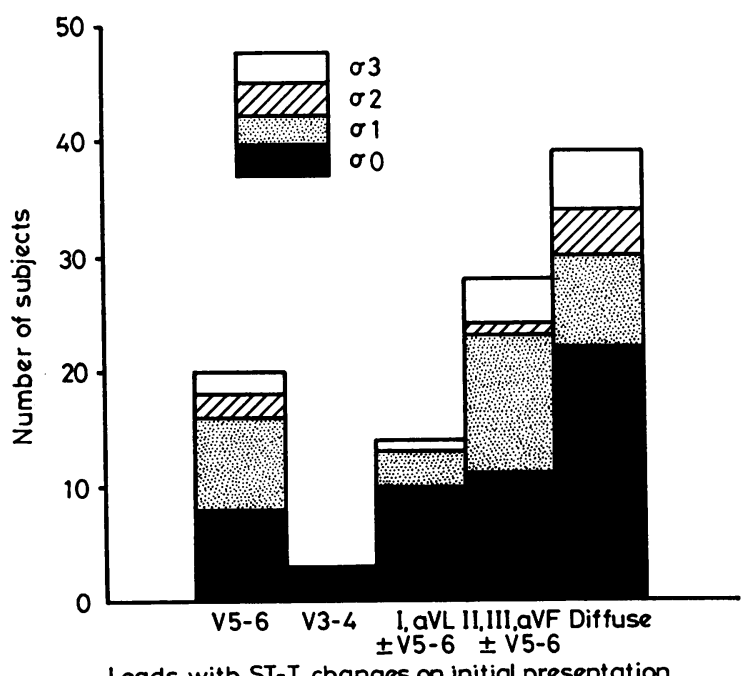

Leads with ST-T changes on initial presentation

Fig. 2 Relation between electrocardiographic presentation and subsequent response to exercise (see also Table). There was no clear correlation between the leads involved at rest and subsequent exercise response. 
The fifth subject with a $\sigma 3$ response was confirmed as having hypertrophic obstructive cardiomyopathy. One further subject with a $\sigma 3$ response was shown to have left ventricular dilatation on echocardiography and one with a $\sigma 2$ response was normal at angiography. A further four subjects with $\sigma 2$ responses together with seven with $\sigma 3$ responses were not further investigated for reasons which included refusal, impending retirement, and certain operational considerations. Five angiograms had been or were performed on subjects without a $\sigma 2$ or $\sigma 3$ response and these were normal.

\section{OTHER CARDIOVASCULAR INCIDENTS}

During the period under review eight pilots (mean age $50.5 \pm$ SEM 3.12 range 35 to 67 ) presented spontaneously with acute myocardial infarction, five of whom had had previously normal electrocardiograms. Two of the remainder had left axis deviation of more than $-30^{\circ}$, and in one of these the axis had shifted abruptly 11 years previously. The third had transient septal $T$ wave notching two years before a septal infarction. Three subjects were found to have suffered "silent" myocardial infarction on routine electrocardiography; their previous electrocardiograms had been normal. One further subject with minor ST-T changes, not investigated at CAA House, had angiographically proven coronary artery disease, three subjects developed angina with normal electrocardiograms, and one is known to have died suddenly. Five cases of symptomatic coronary

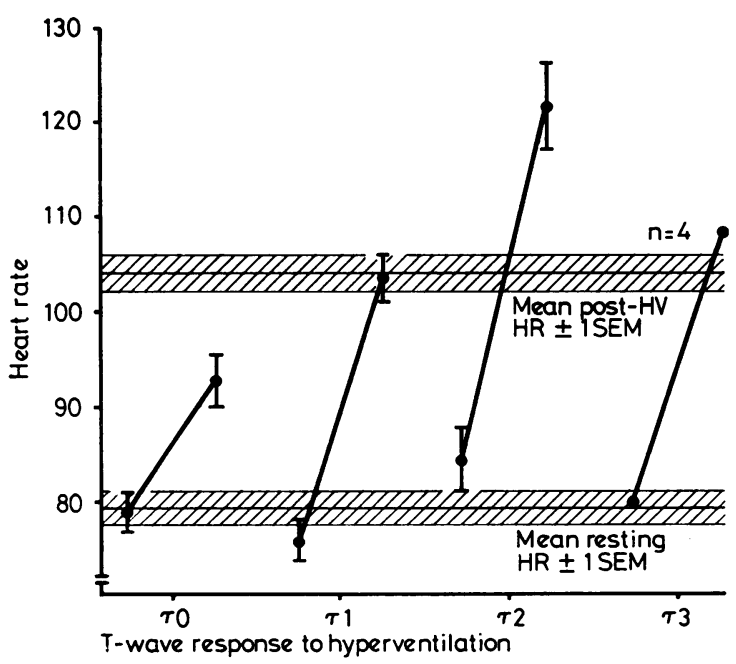

Fig. 3 Resting and post-hyperventilatory heart rates associated with the different $T$ wave responses. All subjects had a significant increase in heart rate on hyperventilation.

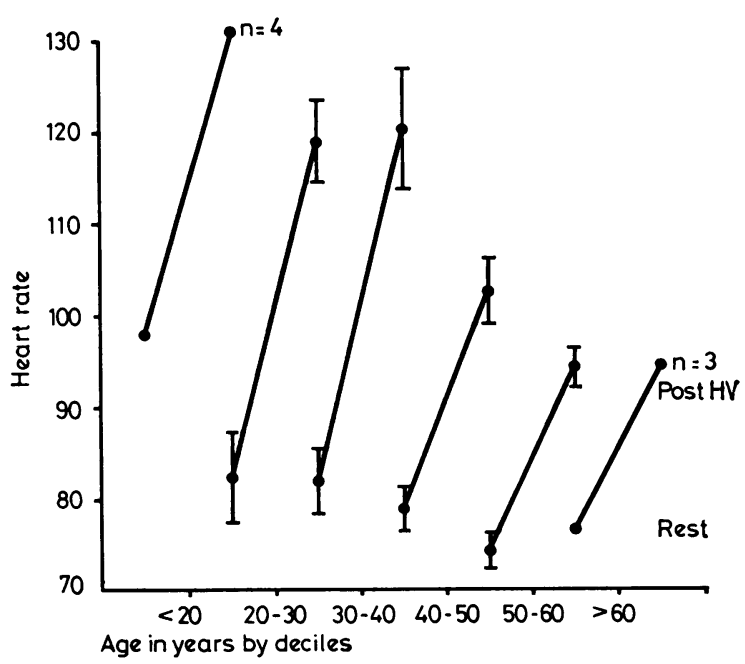

Fig. 4 Relation between heart rate response to hyperventilation and age in deciles. The higher heart rates in the younger age group were associated with more pronounced $\tau$ responses.

artery disease thus occurred per 10000 professional aircrew and air traffic control officers per annum during the period under review.

\section{T WAVE CHANGES IN RELATION TO \\ HYPERVENTILATION}

Fifty-five $(53.4 \%)$ of all subjects showed changes in their ST segments or $\mathrm{T}$ waves to a greater or lesser extent on hyperventilation. Reduction or loss of $\mathrm{T}$ wave was common, occurring in $29(28.2 \%)$ but $\mathrm{T}$ wave inversion was also frequent and occurred in $22(21.4 \%)$. Enhancement was rare and seen in only four subjects. There was no significant difference between the resting heart rates of the $\tau 0$ and $\tau 1$ subjects $(p>0.05)$-see Fig. 3 -though the $\tau 1$ responders were significantly younger (45.69 years \pm 1.91 SEM versus $50.49 \pm 1.29$ SEM $(\mathrm{p}<0.001))$. The $\tau 2$ responders had significantly higher heart rates at rest $(p<0.001)$ and were younger again than their $\tau 1$ peers $(36.45$ years \pm 2.42 SEM versus 45.69 years \pm 1.91 SEM, $\mathrm{p}<0.001$ ). On hyperventilation all subjects increased their heart rates (Fig. 3), there being an inverse relation, though not a simple one, between age and heart rate (Fig. 4), the younger subjects having higher heart rates both at rest and on hyperventilation. No clear relation was evident between the resting electrocardiographic features and the hyperventilatory response (Fig. 5) and hyperventilatory changes were not exclusive to subjects with a normal exercise response (Fig. 6). 


\section{Discussion}

The incidence of minor ST-T changes in the resting electrocardiogram of asymptomatic aviators has been variously reported. Averill and $\mathrm{Lamb}^{23}$ recorded ST segment changes in 0.86 per cent of 67375 United States Air Force personnel while Hiss and Lamb ${ }^{24}$ recorded abnormalities in the $T$ waves of 1.15 per cent of 122043 asymptomatic men. This combined total of 2.01 per cent for ST-T anomalies compares with the United Kingdom experience in which 3.0 per cent of 13842 Royal Air Force and civilian professional aircrew were found to have similar changes. ${ }^{12}$ The probable explanation for the difference between the two countries is differing thresholds for the recording of abnormalities in what were uncoded studies. In the present study 0.74 per cent of the United Kingdom professional aircrew and air traffic control officer population, all with ST-T changes at rest, were evaluated for possible coronary artery disease though one case was subsequently confirmed as having hypertrophic obstructive cardiomyopathy.

One of the problems inevitable in a study such as this is the ethical one of advising coronary angiography in asymptomatic subjects, particularly where the only abnormality is in the electrocardiogram at rest. As complete data on the presence or absence of coronary disease in this population are thus not

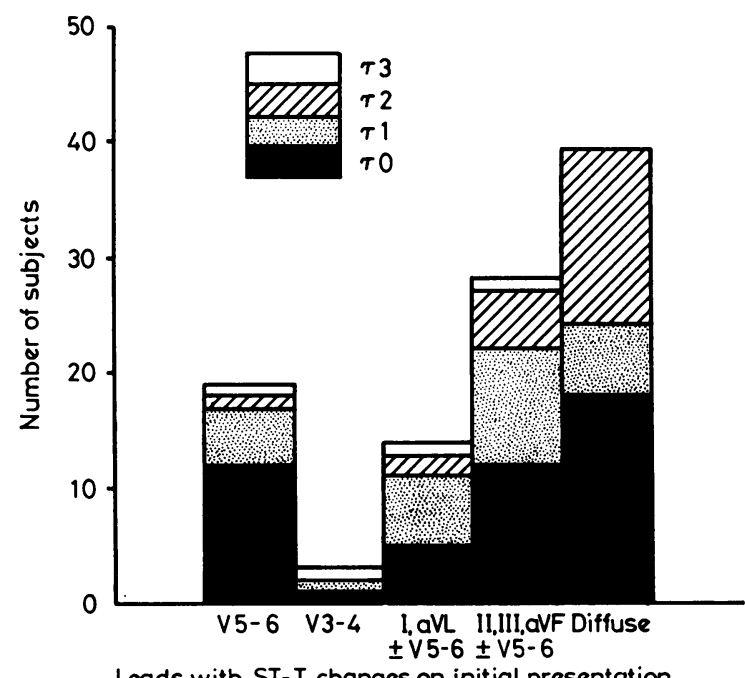

Fig. 5 Relation between electrocardiographic presentation and hyperventilatory response. Patterns of response to hyperventilation $(\tau 1, \tau 2, \tau 3)$ are evenly represented and were not associated with any particular resting electrocardiographic feature.

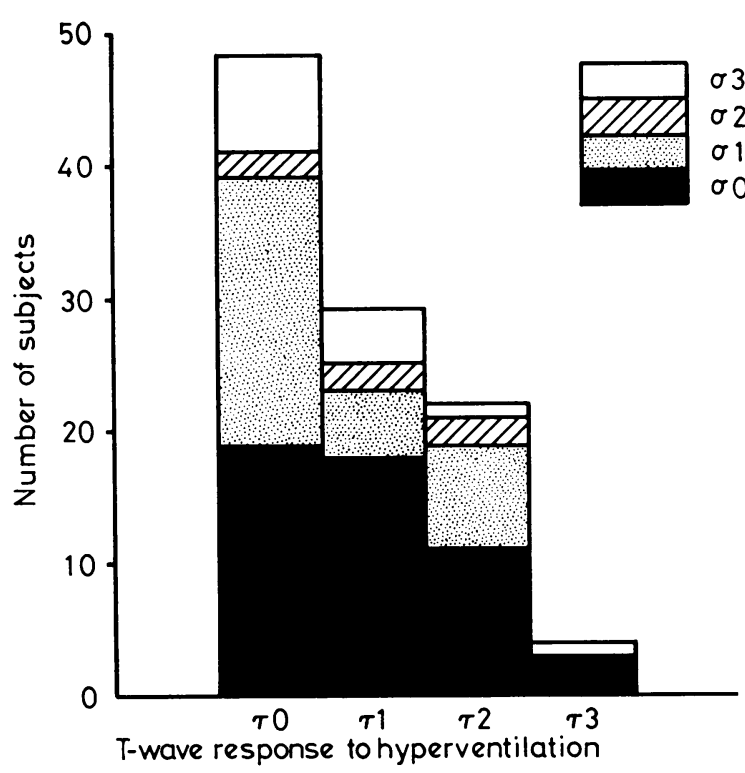

Fig. 6 Relation between exercise response (see also Table) and $T$ wave response to hyperventilation. Hyperventilatory changes were seen in subjects with subsequently proven coronary artery disease.

available, certain assumptions have to be made. Drawing on the observations of Weiner et al..$^{25}$ on their patients with non-cardiac pain, our falsenegative response to exercise would not be expected to exceed a rate of 2 per cent. Applying this figure gives an incidence of significant coronary artery disease in our group of between seven (five with known coronary artery disease plus two falsenegatives) and 19 (five with known coronary artery disease plus two false-negatives plus 12 truepositives) depending on whether the 12 uninvestigated subjects with a positive exercise response were all false-positives or all true-positives. It is proposed to exclude for the purposes of consideration the patient with hypertrophic obstructive cardiomyopathy on the grounds that coronary artery disease was not seriously considered. There was also one known false-positive response, the remaining five normal angiograms having been performed on subjects who were not considered to have positive exercise responses. Given these figures, then the sensitivity of the exercise test lies between 71.4 and 89.5 per cent while its specificity is between 86.3 and 98.8 per cent. The predictive value of the exercise electrocardiogram, dependent upon the true-positive rate, lies becween 27.7 and 94.4 per cent, and the predictive value of the resting electrocardiogram is between 4.9 and 16.7 per cent. 
In reality, three of the uninvestigated group were considered to have such positive responses to exercise that they were virtually certain to have significant coronary disease and if these are included as true-positives and the remainder false-positives, then the values obtained, which may be considered representative, are a sensitivity of 80.0 per cent, a specificity of 89.1 per cent, a predictive value of 44.4 per cent for the exercise electrocardiogram, and a predictive value for the resting electrocardiogram of 7.8 per cent, or of 8.7 per cent if the one pilot with ST-T changes assessed elsewhere is also included.

Comparison between the various published epidemiological studies in exercise electrocardiography and coronary artery disease needs to be cautious in view of differences in technique. Froelicher et al. ${ }^{26}$ found a positive response to exercise in 10.1 per cent of 1390 asymptomatic aircrew while Aronow and Cassidy ${ }^{27}$ obtained a positive response in 8 per cent of a series of 98 men and two women. Based on these observations the subjects in our study, all with minor ST-T changes at rest, had twice the expected rate of a positive exercise response.

The significance of minor resting electrocardiographic changes in the prediction of occult coronary artery disease has been variously reported. Bayes rule $^{28}$ observes that the predictive accuracy of a diagnostic test is dependent upon the prevalence of the disease in the population under scrutiny. In the pilot population the incidence of coronary artery disease is lower than expected, ${ }^{29}$ and thus the predictive value of both the resting and exercise electrocardiograms will be lower. Rose et al. ${ }^{30}$ indicated that $\mathrm{T}$ wave flattening (Minnesota code 5-3) only just achieved significance as a predictor of coronary artery disease in asymptomatic subjects but in symptomatic subjects ST segment (code 4-1, 2,3 ) as well as $T$ wave changes (code $5-2,3$ ) also achieved significance. ST-T changes have also been reported as being significant predictors of sudden cardiac death ${ }^{31}$ but in a study in which two-thirds of the subjects had antecedent coronary artery disease. Our observations suggest that approximately 8 per cent of asymptomatic aircrew with minor ST-T changes at rest have significant coronary artery disease and that three-eighths of those with significant coronary artery disease (whether symptomatic or asymptomatic) will present with these features.

The validity of isolated $T$ wave changes in predicting subsequent coronary artery disease has already been questioned ${ }^{1032}$ and causes of $T$ wave variation commented upon..$^{111219}$ Though only a minority of our subjects could be considered to have labile resting electrocardiograms ( $9 \cdot 7 \%$ of all), we noted repolarisation changes induced by hyperventilation in over half our subjects and felt that this merited further consideration.

The mechanism whereby the $T$ wave becomes flat or inverted on hyperventilation has been extensively examined. It is not attributable to alkalosis, to changes in the position of the heart, or to fluctuation of plasma sodium, potassium, calcium, or magnesium, ${ }^{33}$ and may be abolished by the anticholinergic drug probanthine, suggesting a possible vagal mechanism. Hyperventilation induced a significant tachycardia ${ }^{34}$ in all our subjects which was directly related to the severity of the $T$ wave changes (Fig. 3) and inversely related to age (Fig. 4), suggesting activation of the cardiac sympathetic nerves or possible vagal inhibition or both. Isoprenaline infusion produces identical $T$ wave changes to those of hyperventilation ${ }^{33}$ and resembles those of emotion ${ }^{13}$ as well as those noted by Taggart and his colleagues ${ }^{1}$ during infusion of adrenaline. The balance of evidence at present favours a neural mechanism ${ }^{13}$ involving both sympathetic ${ }^{15} 16$ and parasympathetic components ${ }^{34}$ or the balance between them. How this might influence the epicardial/endocardial repolarisation gradient is unknown but the phenomenon could be explained on the basis of an asynchronous shortening of repolarisation..$^{33}$

The pathophysiological significance of the labile $T$ wave syndrome is uncertain and, though it may be benign, QT prolongation has been described in association with it. ${ }^{16}$ Lary and Goldschlager ${ }^{12}$ have claimed that hyperventilation-induced changes very probably indicate that no coronary artery disease exists. Ten $(18.2 \%)$ of our subjects, however, who showed repolarisation changes on hyperventilation had a positive response to exercise and three of these had angiographically proven coronary artery disease and a further one left ventricular dilatation. It seems more likely, therefore, that the labile $T$ wave syndrome is an independent entity in which a lower incidence of coronary artery disease occurs only because it is a syndrome more common in younger people.

Much effort is put into the detection of cardiovascular disease in professional aircrew and air traffic control officers. The exclusion from flying of anyone with diabetes or significant hypertension makes for a lower than expected prevalence of coronary artery disease, the problem most frequently encountered. At present 5700 resting electrocardiograms and 37 exercise electrocardiograms per 10000 licence holders per annum are performed for the loss of eight licences from significant coronary artery disease, three of whom present with minor 
ST-T changes at routine examination. The removal of even such a small number of aircrew at excess risk from sudden incapacitation would nevertheless be expected to have a favourable influence on air transport safety.

We thank Air Vice-Marshals H B Kelly and J N C Cooke for permission to use their Civil Aviation Authority case records and Dr Geoffrey Bennett, Chief Medical Officer, Civil Aviation Authority, for permission to publish the data. Drs Walter Somerville, Derek Gibson, Michael Webb-Peploe, Douglas Chamberlain, John Coltart, John Hampton, and Professor Peter Sleight kindly arranged further investigations on some of the subjects.

\section{References}

1 Taggart $P$, Carruthers M, Joseph S, et al. Electrocardiographic changes resembling myocardial ischaemia in asymptomatic men with normal coronary arteriograms. Br Heart f 1979; 41 : 214-25.

2 Joy MD. Contribution of resting electrocardiograph to air transport safety (abstract). Br Heart $\mathcal{f}$ 1977; 39: 347 .

3 Joy $M$. The impact of coronary vascular risk factors on professional aircrew licence loss in the UK. Nato AGARD Conference Proceedings, 232, 1977; Neuilly-sur-Seine, pp B191-6.

4 Goldschlager N, Selzer A, Cohn K. Treadmill stress tests as indicators of presence and severity of coronary artery disease. Ann Intern Med 1976; 85: 277-86.

5 Fortuin NJ, Weiss JL. Exercise stress testing. Circulation 1977; 56: 699-712.

6 Robb GP, Marks HH. Postexercise electrocardiogram in arteriosclerotic heart disease. $\mathcal{f} A M A 1967 ; 200$ : 918-26.

7 Doyle JT, Kinch SH. The prognosis of an abnormal electrocardiographic stress test. Circulation 1970; 41: $545-53$.

8 Kreesling CE, Schaaf RS, Lyle AM. Mortality studies of isolated electrocardiographic $T$ wave changes. Proc Life Ins M Dir 1955; 39: 5. (Cited by Ungerleider HE. The prognostic implications of the electrocardiogram. Am f Cardiol 1960; 6: 35-44.)

9 Ungerleider HE. The prognostic implications of the electrocardiogram. Am f Cardiol 1960; 6: 35-44.

10 Higgins ITT, Kannel WB, Dawber TR. The electrocardiogram in epidemiological studies. Reproducibility, validity, and international comparison. $\mathrm{Br} \mathcal{F}$ Prev Soc Med 1965; 19: 53-68.

$11 \mathrm{Kemp}$ GL, Ellestad MH. Significance of hyperventilative and orthostatic $T$-wave changes on the electrocardiogram. Arch Intern Med 1968; 121: 518-23.

12 Lary D, Goldschlager N. Electrocardiographic changes during hyperventilation resembling myo- cardial ischemia in patients with normal coronary arteriograms. Am Heart $\mathcal{f}$ 1974; 87: 383-90.

13 Guazzi M, Fiorentini C, Polese A, Magrini F, Olivari MT. Stress-induced and sympatheticallymediated electrocardiographic and circulatory variations in the primary hyperkinetic heart syndrome. Cardiovasc Res 1975; 9: 342-54.

14 Millar K, Abildskov JA. Notched T waves in young persons with central nervous system lesions. Circulation 1968; 37: 597-603.

15 Kralios FA, Martin L, Burgess MJ, Millar K. Local ventricular repolarisation changes due to sympathetic nerve-branch stimulation. Am F Physiol 1975; 228: 1621-6.

16 Yanowitz F, Preston JB, Abildskov JA. Functional distribution of right and left stellate innervation to the ventricles: production of neurogenic electrocardiographic changes by unilateral alteration of sympathetic tone. Circ Res 1966; 18: 416-28.

17 Gibson DG, Brown DJ. Abnormal left ventricular wall movement in patients with chest pain and normal coronary arteriograms. Relation to inferior $\mathrm{T}$ wave changes and mitral prolapse. $\mathrm{Br}$ Heart $\mathcal{f}$ 1979; 41: 385-91.

18 Oakley GDG, Oakley CM. Abnormal electrocardiograms in athletes (abstract). Br Heart f 1980; 43: 123.

19 Taggart P, Carruthers M, Somerville W. Emotions catecholamines and the electrocardiogram. In: Yu PN, Goodwin JF, eds. Progress in cardiology. Philadelphia: Lea \& Febiger, 1978: 103-24.

20 Bruce RA, Blackmon JR, Jones JW, Strait G. Exercise testing in adult normal subjects and cardiac patients. Pediatrics 1963; 32: 742-56.

21 Doan AE, Peterson DR, Blackmon JR, Bruce RA. Myocardial ischemia after maximal exercise in healthy men. Am Heart $\mathcal{F} 1965$; 69: 11-21.

22 McHenry PL, Morris SN. Exercise electrocardiography-current state of the art. In: Schlant RC, Hurst JW, eds. Advances in electrocardiography. vol 2. New York, San Francisco, and London: Grune \& Stratton, 1976: 265-304.

23 Averill KH, Lamb LE. Electrocardiographic findings in 67,375 asymptomatic subjects. I. Incidence of abnormalities. Am f Cardiol 1960; 6: 76-83.

24 Hiss RG, Lamb LE. Electrocardiographic findings in 122,043 individuals. Circulation 1962; 25: 947-61.

25 Weiner DA, Ryan TJ, McCabe CH, et al. Correlations among history of angina, ST-segment response and prevalence of coronary artery disease in the coronary artery surgery study (CASS). $N$ Engl 7 Med 1979; 301 : 230-5.

26 Froelicher VF Jr, Thomas MM, Pillow C, Lancaster MC. Epidemiologic study of asymptomatic men screened by maximal treadmill testing for latent coronary artery disease. Am $\mathcal{F}$ Cardiol 1974; 34: $770-6$.

27 Aronow WS, Cassidy J. Five-year follow-up of double Master's test, maximal treadmill stress test, and resting and postexercise apexcardiogram in asymptomatic persons. Circulation 1975; 52: 616-8. 
28 Jelliffe RW. Quantitative aspects of clinical judgement. Am f Med 1973; 55: 431-3.

29 Kulak LL, Wick RL Jr, Billings CE. Epidemiological study of in-flight airline pilot incapacitation. Aerospace Med 1971; 42: 670-2.

30 Rose G, Baxter PJ, Reid DD, McCartney P. Prevalence and prognosis of electrocardiographic findings in middle-aged men. $\mathrm{Br}$ Heart $\mathcal{f}$ 1978; 40: 636-43.

31 Friedman GD, Klatsky AL, Siegelaub AB. Predictors of sudden cardiac death. Circulation 1975; 51, Suppl III : 164-75.

32 Blackburn H, Taylor HL, Keys A. Coronary heart disease in seven countries. XVI. The electrocardio- gram in prediction of 5-year coronary heart disease incidence among men aged forty through fifty-nine. Circulation 1970; 41, Suppl I: 154-61.

33 Biberman L, Sarma RN, Surawicz B. T-wave abnormalities during hyperventilation and isoproteronol infusion. Am Heart f 1971; 81 : 166-74.

34 Wasserburger RH, Siebecher KL Jr, Lewis WC. The effect of hyperventilation on the normal adult electrocardiogram. Circulation 1956; 13: 850-5.

Requests for reprints to Dr M Joy, Civil Aviation Authority, CAA House, London WC2. 